\title{
Endoscopic intraluminal vacuum therapy of duodenal perforation
}
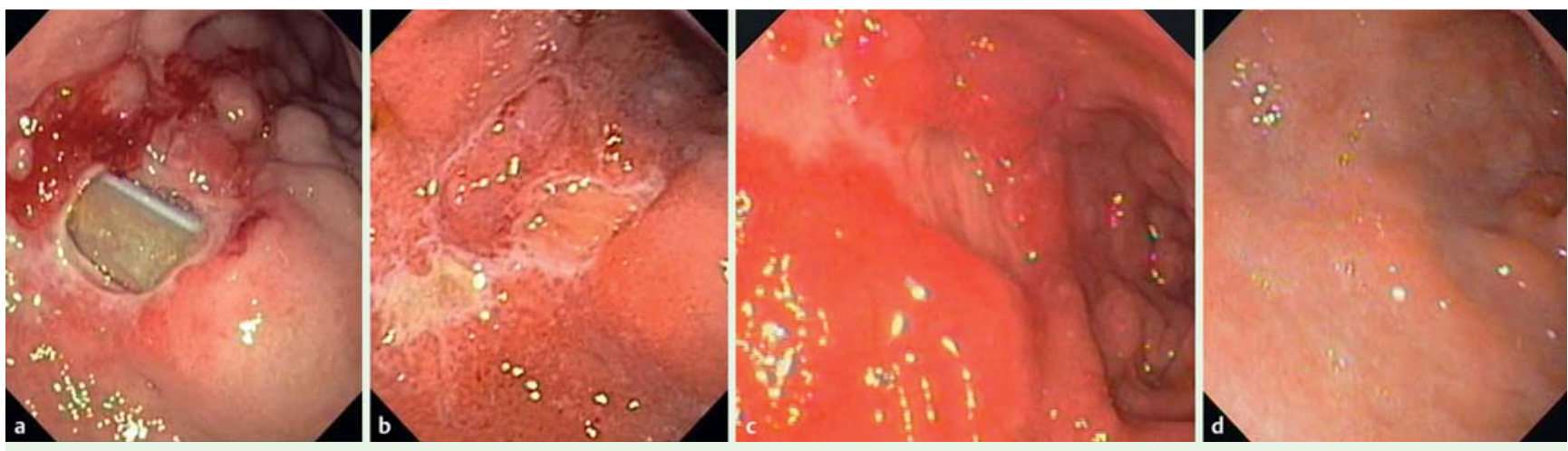

Fig. 1 Progression of treatment response following endoscopic intraluminal vacuum therapy of a duodenal perforation. a Duodenal perforation. b End of therapy on Day 7. c At 5 days post-treatment. d At 6 months post-treatment.

Since 2006, we have been developing a technique that allows placement of an endoscopic vacuum sponge under direct endoscopic visualization [1 -3]. A patient underwent jejunal segment resection of an isolated small metastasis. At the duodenojejunal anastomosis, a drainage catheter (Passive Drainage Ch.21, Primed ${ }^{\circledR}$, Halberstadt, Germany) was placed intraoperatively. On Day 6, bilious material was observed discharging through the perianastomotic drain. Computed tomography scan found a large retropancreatic fluid accumulation. The patient had no clinical symptoms. An endoscopic examination was carried out and revealed that the drainage tube had perforated the duodenal bulb, resulting in a circumscribed defect of $15 \mathrm{~mm}$, with an otherwise intact anastomosis and no signs of mucosal ischemia $(\bullet$ Fig. 1 a).

Instead of intracavitary placement, an intraluminal placement of the sponge was utilized to treat the compartmentalized perforation defect. Under general anesthesia a stomach tube (Vetrol ${ }^{\mathrm{TM}}, 14 \mathrm{Ch} \times$ $120 \mathrm{~cm}$, Mallinckrodt Medical, Athlone, Ireland) was inserted through the nose, the distal tip was lead out orally, shortened, inserted in polyurethane foam (Endo-SPONGE ${ }^{\circledR}$, B-Braun Medical Ltd., Sheffield, UK) and secured by suture. The sponge was size-adjusted and grasped with a tripod-equipped endoscope, and then introduced into the duodenal lumina and onto the defect under direct endoscopic visualization. A suction pressure of $125 \mathrm{~mm} \mathrm{Hg}$ was applied, resulting in the intraluminal fixation of the sponge, occlusion of the duodenum, and successive cessation of bilious discharge. A second transnasal stomach tube drained the gastric fluids.

After 2 days the suction was discontinued, and the sponge was gently extracted. The mucosa surrounding the defect showed reddening and subtle erosions. The vacuum sponge system was replaced and the perianastomotic drain removed.

After a total of 7 days and one system change, the intraluminal vacuum therapy was stopped. A small ulcer remained at the site of the defect ( $\boldsymbol{F i g} \mathbf{1} \mathbf{1}$ ). Full oral nutrition began 2 days after removal of the vacuum sponge. A check-up examination 5 days later showed a small superficial ulcer ( $\bullet$ Fig. 1 c).

Follow-up endoscopy at 6 months posttherapy showed normal duodenal mucosa without any stenosis ( $\bullet$ Fig. $\mathbf{1}$ d).

Competing interests: Dr Loske and Professor Mueller have received honoraria from BBD Aesculap for organizing and performing a workshop dealing with vacuum therapy of anastomotic dehiscence following resections in the upper and lower gastrointestinal tract.

Endoscopy_UCTN_Code_TTT_1AO_2AI

\section{G. Loske, T. Schorsch, C. T. Mueller}

Department of Surgery, Katholisches Marienkrankenhaus, GmbH, Hamburg, Germany

\section{References}

1 Argenta LC, Morykwas MJ. Vacuum-assisted closure: a new method for wound control and treatment: clinical experience. Ann Plast Surg 1997; 38: $563-576$

2 Weidenhagen $R$, Gruetzner KU, Wiecken $T$ et al. Endoscopic vacuum-assisted closure of anastomotic leakage following anterior resection of the rectum: a new method. Surg Endosc 2008; 22: $1818-1825$

3 Loske G, Muller C. Vacuum therapy of an esophageal anastomotic leakage - a case report. Zentralbl Chir 2009; 134: 267-270

Bibliography

DOI $10.1055 / \mathrm{s}-0029-1243940$

Endoscopy 2010; 42: E109

(c) Georg Thieme Verlag KG Stuttgart · New York . ISSN 0013-726X

\section{Corresponding author \\ G. Loske, MD}

Department of Surgery

Katholisches Marienkrankenhaus, $\mathrm{GmbH}$

Alfredstraße 9

22087 Hamburg

Germany

Fax: +49-40-25461400

loske.chir@marienkrankenhaus.org 